\title{
Association between Emotional State Changes in Infertile Couples and Outcome of Fertility Treatment
}

\section{Verbindung zwischen Änderungen der emotionalen Befindlichkeit bei unfruchtbaren Paaren und das Outcome von Unfruchtbarkeits- behandlungen}

\section{(ㄷ) (1) (우) $\Theta$}

\section{Authors}

Erika Gabnai-Nagy ${ }^{1}$, Antal Bugán ${ }^{1}$, Béla Bodnár², Gábor Papp ${ }^{3}$, Beáta Erika Nagy ${ }^{4}$

\section{Affiliations}

1 Institute of Behavioural Sciences, Faculty of Public Health, University of Debrecen, Debrecen, Hungary

2 Assisted Reproduction Center, Clinical Centre, University of Debrecen, Debrecen, Hungary

3 Institute of Psychology, Faculty of Humanities, University of Debrecen, Debrecen, Hungary

4 Department of Pediatrics, Faculty of Medicine, University of Debrecen, Debrecen, Hungary

\section{Key words}

infertility, assisted reproductive technology (ART), positive and negative affectivity, depression, anxiety

\section{Schlüsselwörter}

Infertilität, assistierte Reproduktion, positive und negative Affektivität, Depression, Angst

$$
\begin{array}{ll}
\text { received } & 18.4 .2018 \\
\text { revised } & 14.12 .2018 \\
\text { accepted } & 10.2 .2019
\end{array}
$$

Bibliography

DOI https://doi.org/10.1055/a-0854-5987

Geburtsh Frauenheilk 2020; 80: 200-210 @ Georg Thieme Verlag KG Stuttgart · New York | ISSN 0016-5751

\section{Correspondence}

Erika Gabnai-Nagy

University of Debrecen, Institute of Behavioural Sciences

Nagyerdei krt. 98., 4032 Debrecen, Hungary

nagyerika16@gmail.com

\section{ABSTRACT}

Aims Infertility and its treatment are associated with considerable psychological distress for infertile couples. The aim of our study was to explore to what extent positive and negative affectivity and a predisposition to depression and anxiety appear in infertile couples during in vitro fertilization (IVF) treatment. We also aimed to explore how the emotional state of couples changed during IVF in relation to treatment outcomes.

Method In our longitudinal study, 174 people (87 couples) were followed up during treatment by means of questionnaires. Their emotional state was assessed with PANAS, BDI-R, and STAI at the beginning of treatment, before embryo transfer, and before taking a pregnancy test. Couples who achieved pregnancy after treatment were included in the successful group $(n=82)$, while those who did not were included in the unsuccessful group ( $n=92)$.

Results We found more favorable emotional states in IVF couples compared to patient populations and the average population. In successful IVF couples, positive affectivity decreased, and negative affectivity increased in women until the time of embryo transfer. This was accompanied by an increase in positive affectivity in men, which remained until the time of the pregnancy test and provided emotional support to their partner. These results were confirmed by changes in the levels of depression.

Conclusion Our study suggests the importance of couples' emotional dynamics for having a child and an association between couples' emotional reactions during IVF cycles and treatment success.

\section{ZUSAMMENFASSUNG}

Zielsetzung Unfruchtbarkeit und deren Behandlung gehen bei unfruchtbaren Paaren mit erheblichem psychischen Disstress einher. Ziel unserer Studie ist die Erörterung der Frage, in welchem Maße die positive und negative Affektivität, die Neigung zur Depression und Angst bei unfruchtbaren Paaren während einer In-vitro-Fertilisation (IVF) typisch sind. Des 
Weiteren wurde auch untersucht, wie sich der Gefühlszustand der Paare mit dem Ausgang der Behandlung während des IVFZyklus änderte.

Methode Während der Behandlung wurden im Rahmen einer longitudinalen Studie 174 Personen (87 Paare) mit Fragebogen gewertet. Am Anfang der Behandlung, vor dem Embryotransfer und vor der Schwangerschaft wurde ihr Gefühlszustand mit PANAS-, BDI-R- und STAI-Fragebögen eingeschätzt. Paare mit Schwangerschaft als Ergebnis der Behandlung wurden in die erfolgreiche Gruppe eingeordnet $(n=82)$, die anderen ohne Schwangerschaft als Ausgang dagegen in die nicht erfolgreiche $(n=92)$.

Ergebnisse Positive und negative Affektivität der unfruchtbaren Paare demonstrieren signifikant bessere Werte im Vergleich zum Durchschnitt der somatisch Kranken, ihre Depres- sion und Angst sind weniger ausgeprägt als bei dem Durchschnitt der ungarischen Population. Im Falle der erfolgreichen Paare senken sich die positiven Gefühle der Frauen und erhöhen sich die negativen bis zum Zeitpunkt des Embryotransfers. Gleichzeitig erhöhen sich die positiven Gefühle des Mannes des erfolgreichen Paares in Erwartung eines Erfolgs und gewähren damit ihrer Partnerin eine positive Unterstützung. Diese Tendenz wird von den Veränderungen des Wertes der Depression untermauert. Bei den nicht erfolgreichen Paaren sind andere Tendenzen zu beobachten.

Schlussfolgerungen Unsere Studie demonstriert, dass die Gefühlsdynamik der Beziehung der Paare eine entscheidende Rolle bei dem Kinderwunsch spielt und es einen Zusammenhang zwischen den emotionalen Reaktionen der Paare während des IVF-Zyklus und dem Behandlungserfolg gibt.

\section{Introduction}

Infertility is clinically defined as "the failure to achieve a clinical pregnancy after 12 months or more of regular unprotected sexual intercourse" [1]. Infertility has become a worldwide public health problem due to that fact that it affects up to $15 \%$ of reproductiveaged couples worldwide [2]. According to the epidemiological data, one in every six couple struggles against infertility in Hungary [3].

Infertility can be caused by a female, male factor, a combination of female and male factor, or an idiopathic factor. Approximately $40 \%$ of infertility is due to a female factor (e.g. anovulation, endometriosis) and $40 \%$ to a male factor (e.g. ejaculatory dysfunction), and about $15 \%$ of couples do not display any objective alteration leading to a definite diagnosis $[4,5]$.

In fact, there is a continuing expansion of the number of assisted reproductive technologies (ART) treatment cycles including In Vitro Fertilization and Embryo Transfer (IVF-ET) in Europe [6]. The in vitro fertilization and embryo transfer can be divided into four steps:

1. hormonal stimulation, monitoring, ultrasound,

2. oocyte retrieval,

3. fertilization, cleavage,

4. embryo transfer.

The goal of hormonal stimulation is to create numerous oocytes for manipulation for IVF and transfer by stimulating the woman's ovulatory process. Monitoring of oocyte development and endometrial thickness and patterns is also included. Transvaginal ultrasound-guided oocyte aspiration occurs after terminating of the ovarian stimulation. After which the egg and sperm are prepared for fertilization (IVF or ICSI), embryos are transferred into the uterus [7]. As a matter of fact, five IVF cycles are funded by the National Health Insurance Fund of Hungary. Nowadays, the results of such treatment show that approximately $35 \%$ of IVF treatments are successful in Hungary [8].

In spite of the fact that, there are infertile couples that show resilience throughout their infertility and treatment experience, infertility is often associated with considerable psychological dis- tress and emotional problems [9-11]. With regard to comparison of emotional state in infertile and control population, findings are contradictory [12-15]. Most studies suggest that IVF couples show more negative emotional state than the community controls. In fact, the majority of the research results are attributed by studies and investigations conducted outside Hungary, with comparatively little data from Hungarian populations.

There is increasing evidence that emotional factors (e.g. anxiety, depression) are related to IVF treatment outcome. Higher levels of anxiety and depression have been associated with lower pregnancy rates in several studies [16-18]. In contrast, a metaanalysis of 14 prospective studies has found no statistically significant difference between women who achieved a pregnancy after a cycle of ART and those who did not in pretreatment emotional distress (e.g. anxiety, feelings of tension, depression) [19]. Furthermore, according to a meta-analysis including 31 prospective studies, a negative association has been found between both trait and state anxiety and the outcome of ART, whereas there has been no significant association between depression and clinical pregnancy [20].

As regards couples' emotional state changes during the treatment, few studies have compared the emotional status of infertile couples at different stages of the IVF cycle, particularly the association between changes in psychological factors and the IVF success. Yong et al. [21] have reported similar anxiety scores in women undergoing IVF treatment before embryo transfer and before pregnancy test; furthermore, they tend to be most vulnerable to psychological distress at the stage of pregnancy test. Turner et al. [22] have found that lower level of state anxiety of IVF women one day prior to oocyte retrieval is associated with higher pregnancy rate, while Lintsen et al. [23] suggest that the anxiety gain score from pretreatment to oocyte retrieval does not affect the pregnancy rate after IVF.

Despite the large number of studies conducted to examine the effect of psychological factors on the IVF success, still little is known about changes in emotional reactions of both partners over the course of the cycle and experience of couples who achieved pregnancy and those who did not. Investigating the couples' emotional reactions during the treatment may provide valu- 
able information that may help improve support before and during the treatment. Thus, the present study aimed to explore to what extent the positive and negative affectivity, the predisposition for depression and anxiety appear among infertile couples during the IVF treatment and how the results relate to the emotional state of the general and patient populations. Moreover, we aim to test the differences between the emotional states of infertile couples at determinant stages of the treatment in association with the outcome of it.

\section{Materials and Methods}

\section{Participants}

Altogether 174 people (87 couples) took part in our research. 87 women and 87 men entering IVF treatment completed selfreport questionnaires.

The participants were recruited using simple random sampling at an Assisted Reproductive Centre in Hungary, which was a private center at the time of the research, but since 1st of January 2018 , it has become again a university institution.

Participation required couples

1. to be at least 18 years of age,

2. to be about to begin an IVF cycle during the time of data collection,

3. and to have the ability to read and write in Hungarian language and to be able to complete the questionnaires.

Couples were excluded from the study if

1. one or both of the partners had a psychiatric diagnosis,

2. or were currently receiving psychological care.

The study was approved by the Human Reproduction Committee of the Medical Research Council in Hungary, and informed consent was obtained from all participants.

\section{Procedure}

The study is a prospective, longitudinal study in which couples (both men and women) were followed by means of questionnaires at the following significant stages of the IVF treatment: at the beginning of the treatment (T1), before embryo transfer (T2), and before pregnancy test (T3). GnRH-a (gonadotropin-releasing hormone agonists) short or long protocols were used for ovarian stimulation in IVF cycles in accordance with age and previous history. The long protocol was applied in patients under the age of 35 years, while the short protocol was applied in patients aged 35 years or over. In $90 \%$ of cases, we used recombinant folliclestimulating hormone ( $\mathrm{rFSH})$ and recombinant luteinizing hormone (rLH) as well as recombinant human chorionic gonadotropin (hCG). Only in $10 \%$ of cases, we used urinary human menopausal gonadotropin (uhMG). Patients were invited to participate in the study personally with written information about the study.

Of the 105 couples invited, 104 agreed to participate in the study (99\% participation rate). We have elected participants in our study who were about to begin their first (62 couples) or second ( 25 couples) IVF treatment, as we had assumed that each failed treatment may increase levels of depression, anxiety and psychological distress among infertile couples, thereby not allowing us to compare couples with no or a short history of infertility treatment and couples with a longer one.

Couples were given the first questionnaire set before the hormonal treatment started, and asked to complete it at home, and then bring back by the time of the next visit. The second questionnaire set was given to the couples at the stage of oocyte retrieval to fill in on the day before embryo transfer. Finally, the third questionnaire set was given to the couples at the stage of embryo transfer to complete on the day before the pregnancy test. At the second measurement occasion one man, while at the third measurement occasion three men and two women did not complete the questionnaire set.

Subsequently, we divided the study group into two subgroups depending on the IVF treatment outcome. Couples who achieved pregnancy after treatment were included in the successful group $(n=82)$, whereas couples who did not achieve pregnancy after IVF were included in the unsuccessful group $(n=92)$. Pregnancy status was defined by a positive serum $\beta$-hCG test result two weeks after embryo transfer.

\section{Measurements}

First measurement occasion (T1)

The participants completed a demographic and infertility-specific questionnaire and three psychological questionnaires described in detail below.

\section{Demographic and infertility-specific questionnaire}

This questionnaire included questions concerning gender, age, marital status, duration of marriage or cohabitation, residence, qualification, current employment, subjective evaluation of financial status, duration and cause of infertility, and number of previous IVF treatments.

\section{Positive and Negative Affect Schedule}

Positive and negative emotional states of couples were assessed using the Positive and Negative Affect Schedule (PANAS). The original questionnaire was developed by Watson et al. [24]. This measurement contains twenty items, ten describing positive (e.g. enthusiastic, attentive) and ten describing negative (e.g. upset, irritable) personality traits, which the individuals should judge on a fivepoint Likert scale how they feel with regard to each statement (from 1 = very slightly, or not at all, to $5=$ very much) [25]. It can be used with both long-term (e.g. past year or general) and shortterm instructions (e.g. right now or today) [24]. In the present study, participants were asked to rate how they felt at the present moment. The higher the positive affectivity score, the more positive the current emotional state is. The higher the negative affectivity score, the more negative the current emotional state is. The Cronbach alpha coefficient of the negative affectivity subscale was 0.88 , while 0.8 for the positive affectivity subscale, suggesting that both subscales have high internal consistency.

\section{Beck Depression Inventory}

Depression was measured by the short form of the Beck Depression Inventory (BDI-R). The original version of the instrument is one of the most widely used inventories for measuring character- 
istic attitudes and symptoms of depression with very good validity and reliability [26]. The BDI has been developed in different forms, including the 9-item short form. The nine items refer to social withdrawal, indecisiveness, sleep disorders, fatigue, excessive worrying of physical symptoms, inability to work, pessimism, dissatisfaction, inability to feel pleasure, and self-blame [27]. The participants were asked to respond to each item on a four-point Likert scale (from $1=$ not at all, to 4 = very much), indicating the extent to which the statement describes them. The higher the score, the higher the occurrence of depressive symptoms is. Although this inventory is not suitable for diagnosing depression, it can be applied to monitor mood state changes in both research and therapy [28]. The Cronbach alpha coefficient of 0.77 demonstrates good internal consistency.

\section{Spielberger State-Trait Anxiety Inventory}

The couples' state and trait anxiety were assessed using the Spielberger State-Trait Anxiety Inventory (STAI). The widely used 40-item self-report questionnaire with two subscales was developed for measuring the severity of anxiety, which is a reliable indicator of two types of anxiety, the state and trait anxiety. The state anxiety scale (A-State) evaluates the current state of anxiety, asking how the individual feels "right now", whereas the trait anxiety scale (A-Trait) evaluates relatively stable "personality dependent" anxiety, namely the predisposition to anxiety. It contains 20 items for assessing trait anxiety and 20 items for state anxiety. The participants were asked to respond to each item on a four-point Likert scale (from 1 = not at all, to 4 = very much), indicating the extent to which the statement describes them. Higher scores indicate greater anxiety [29]. The Cronbach alpha coefficient of the state anxiety scale was 0.94 , while 0.7 for the trait anxiety scale, suggesting that the subscales have acceptable internal consistency.

\section{Second measurement occasion (T2)}

The participants completed the questionnaires detailed above measuring transient psychological variables, namely PANAS, BDI-R, and A-State.

\section{Third measurement occasion (T3)}

The same questionnaires were applied as at the second measurement occasion.

\section{Data analysis}

In order to explore the differences in the demographic and reproductive characteristics between the successful and unsuccessful IVF groups, we performed an independence test.

The following research questions were examined:

1. whether IVF couples do differ from the general adult and patient populations with regard to emotional state (positive and negative affectivity, depression, anxiety) during the treatment, and how specific the negative change in emotional state and depression is to them;

2. how the emotional states of infertile couples change over the course of the IVF cycle in association with the treatment outcome, and what emotional process is associated with it.
In comparison with the general adult population, we compared our findings with the published results of Hungarostudy 2013 survey [30], a cross-sectional survey enrolling a large nationally representative sample of the Hungarian population aged $>18$ years $(n=2000)$ (mean age $=46.9$ years; $S D=18.24 ; 46.6 \%$ male). The survey aimed to examine the biopsychosocial status and potential risk factors of the general Hungarian population.

In comparison with the patient population, we compared our findings with the published results of Gyollai and his colleagues [25], who examined Hungarian patients $(n=466)$ visiting their General Practitioners for various somatic complaints (mean age $=44.76$ years; $S D=15.04 ; 36.9 \%$ male). The study aimed to investigate the psychometric properties of the Hungarian version of the original and the short form of the Positive and Negative Affect Schedule (PANAS).

Comparisons of our study participants and reference groups could act as confounding factors in the interpretation of results, due to their different study design.

Before the detailed examination of research questions, we used the Kolmogorov-Smirnov test for testing normality. In the case of normal distribution, we used parametric tests, while if the data were not normal, we used non-parametric tests.

One-sample t-tests were applied in order to compare mean scores of our sample and the mean scores found in the samples of the reference groups (general adult and patient populations) after examining the assumptions of the one-sample t-test. Repeated measures ANOVA was performed to test the emotional state changes during the treatment in respect of the success of the treatment after examining the assumptions of the repeated measures ANOVA. Our between-subjects factor (treatment outcome) only had two groups (successful and unsuccessful), thus we did not perform post hoc tests.

Statistical significance was defined as $p<0.05$. The statistical analyses were conducted with the Statistical Package for the Social Sciences (SPSS) version 22.0.

\section{Results}

\section{Descriptive statistics}

The study sample consisted of 87 couples who were about to begin a trial of IVF. - Table 1 summarizes the demographic and reproductive characteristics of the 174 participants in the sample.

We found no remarkable difference between the successful and unsuccessful IVF groups, except for the cause of infertility. It can be seen from the $\mathbf{r}$ Table $\mathbf{1}$ that compared to the successful IVF group, idiopathic infertility was observed in the unsuccessful IVF group to a greater extent (9.76 vs. $23.91 \%$ ). Due to the fact that there was no remarkable difference between the successful and unsuccessful IVF women in respect of age either (successful group: mean age $=32.39$ years, $\mathrm{SD}=3.78$; unsuccessful group: mean age $=34.85$ years, $S D=4.89$ ), the proportions of patients treated with short or long GnRH-a protocol were comparable in both groups, just as in the case of the applied stimulation drugs. Consequently, the type of the applied protocols and stimulation drugs does not act as a confounding factor in the comparison of 
- Table 1 Demographic and reproductive characteristics of participants $(n=174)$.

\begin{tabular}{|c|c|c|}
\hline Variable & $\begin{array}{l}\text { Successful } \\
\text { IVF group } \\
(\mathrm{n}=82)\end{array}$ & $\begin{array}{l}\text { Unsuccessful } \\
\text { IVF group } \\
(\mathbf{n}=92)\end{array}$ \\
\hline \multicolumn{3}{|l|}{ Age (years) } \\
\hline - Mean (SD) & $34.05(0.73)$ & $36.51(1.23)$ \\
\hline - Median & 34.50 & 36 \\
\hline - Range & $24-49$ & $26-58$ \\
\hline \multicolumn{3}{|l|}{ Marital status (\%) } \\
\hline - Marriage & 85.37 & 76.09 \\
\hline - Cohabitation & 14.63 & 23.91 \\
\hline \multicolumn{3}{|l|}{$\begin{array}{l}\text { Duration of marriage/ } \\
\text { cohabitation (\%) }\end{array}$} \\
\hline - $0-2$ years & 14.63 & 23.91 \\
\hline - 2-4 years & 29.27 & 10.87 \\
\hline - 4-6 years & 12.20 & 10.87 \\
\hline - >6 years & 43.90 & 54.35 \\
\hline \multicolumn{3}{|l|}{ Residence (\%) } \\
\hline - Urban area & 87.80 & 84.78 \\
\hline - Rural area & 12.20 & 15.22 \\
\hline \multicolumn{3}{|l|}{ Education (\%) } \\
\hline - Primary school & 2.44 & 1.09 \\
\hline - Secondary level & 50 & 54.34 \\
\hline - Higher education & 47.56 & 44.57 \\
\hline \multicolumn{3}{|c|}{ Current employment (\%) } \\
\hline - Full-time job & 86.90 & 84.78 \\
\hline - Part-time job & 2.38 & 4.35 \\
\hline - Disabled & 0 & 0 \\
\hline - Retired & 1.19 & 1.09 \\
\hline - Casual work & 0 & 0 \\
\hline - Unemployed & 4.76 & 6.52 \\
\hline - Other & 2.38 & 3.26 \\
\hline \multicolumn{3}{|l|}{$\begin{array}{l}\text { Subjective evaluation } \\
\text { of financial status (\%) }\end{array}$} \\
\hline - Very bad & 2.44 & 1.09 \\
\hline - Acceptable & 23.17 & 25 \\
\hline - Average & 46.34 & 42.39 \\
\hline - Good & 28.05 & 25 \\
\hline - Very good & 0 & 6.52 \\
\hline \multicolumn{3}{|c|}{ Duration of infertility (years) } \\
\hline - Mean (SD) & $3.99(2.85)$ & $4.21(2.75)$ \\
\hline \multicolumn{3}{|l|}{ Cause of infertility (\%) } \\
\hline - Female factor & 34.15 & 30.43 \\
\hline - Male factor & 26.83 & 19.57 \\
\hline - Combined & 29.27 & 26.09 \\
\hline - Idiopathic & 9.76 & 23.91 \\
\hline
\end{tabular}

successful and unsuccessful IVF groups regarding emotional state changes during the treatment.

\section{Comparison of IVF couples and reference groups regarding emotional state}

Firstly, we examined the characteristics of the emotional state in infertile couples with regard to IVF treatment compared to the general adult and patient populations.

First of all, with regard to negative and positive emotional states, we compared the IVF couples' negative and positive affectivity with the mean scores of a Hungarian patient sample $(n=466)$ in which patients visited their General Practitioners for a variety of somatic complaints [25]. According to the results, the negative affectivity scores of both IVF men and women were significantly lower than male and female patients' scores at every stage of the treatment (for details see $>$ Table 2 ). As regards the differences in positive emotional state, IVF men and women showed significantly higher level of positive affectivity than their male and female controls from the patient population during the whole cycle.

With regard to depression and anxiety, we compared the IVF couples' depression and anxiety scores with the mean scores of the general adult Hungarian population $(n=2000)$ [30]. It can be seen from the $>$ Table 2 that compared to the comparative norms, IVF men's depression scores were significantly lower than those of the general adult population at T1, T2 and T3, just as among women.

Surprisingly, the trait anxiety level of IVF couples was significantly lower than the scores of the general adult Hungarian population. We found no remarkable difference in state anxiety between the infertile men and the representative sample. As for women's state anxiety, IVF women experienced significantly lower level of state anxiety than the female controls at $\mathrm{T} 1$ (T1: $\mathrm{t}[51]=$ $-3.858, \mathrm{p}<0.01)$ and $\mathrm{T} 3$ (T3: $\mathrm{t}[48]=-3.655, \mathrm{p}<0.05)$.

In summary, more positive results were observed among the IVF couples than the reference groups. The positive and negative affectivity of the IVF couples are better compared to the patient population; they feel less depressed and show a lower level of trait anxiety than the average population. Furthermore, their state anxiety level is on average.

\section{Comparison of successful and unsuccessful IVF groups regarding emotional state changes during the treatment}

Secondly, we examined if there are significant differences between the successful and unsuccessful IVF groups in the emotional state including positive and negative affectivity and depression over the course of the IVF cycle.

- Fig. 1 and Fig. 2 illustrate changes in the positive and negative emotional states of the successful and unsuccessful IVF couples. It is clearly depicted that the positive emotions are remarkably higher than the negative ones during the entire duration of the treatment. 
- Table 2 Comparison of IVF couples $(\mathrm{n}=174)$ with comparative norms.

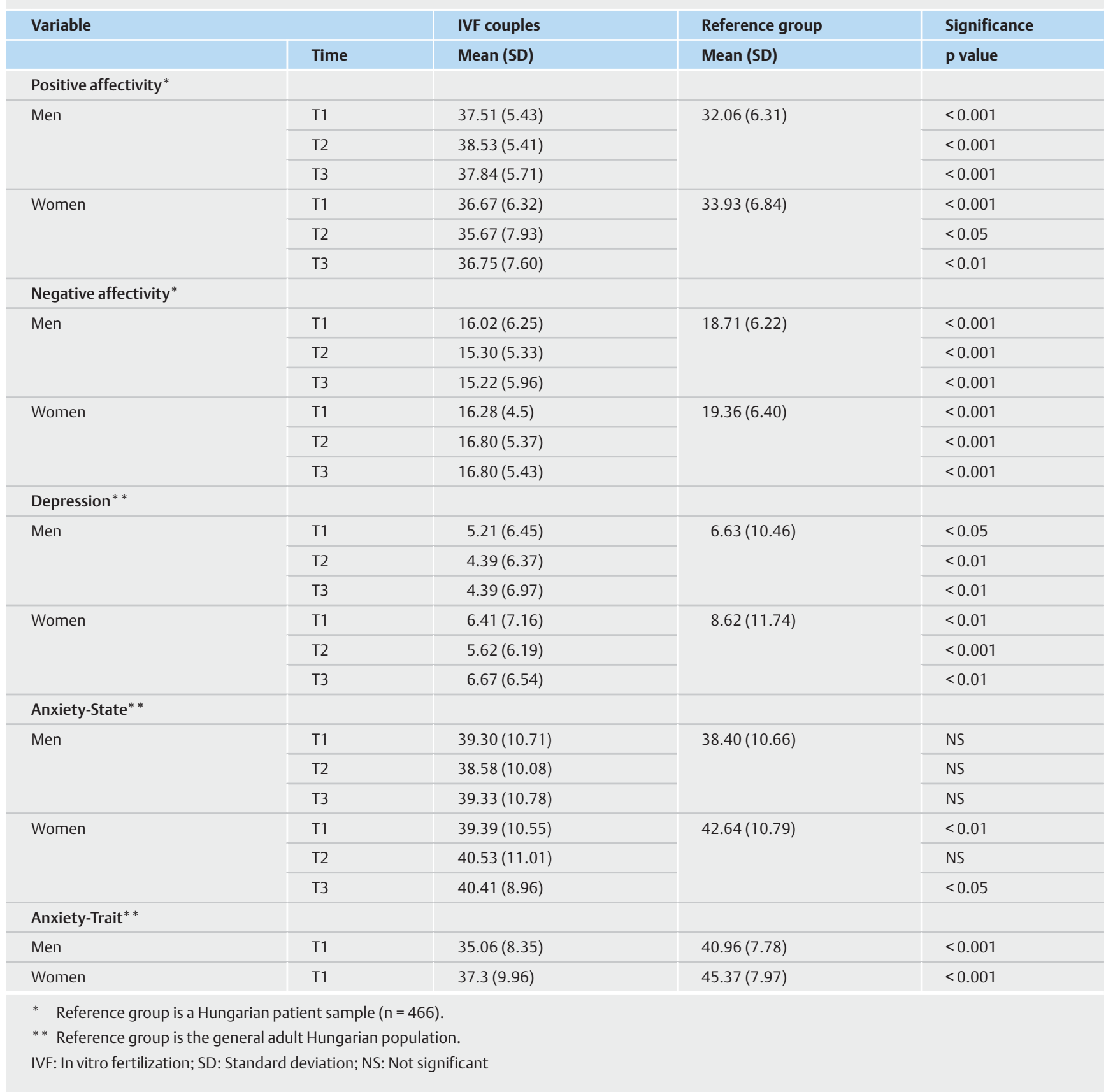

With regard to women's comparison ( $\bullet$ Fig. 1 ), a decrease in positive emotions can be observable in both successful and unsuccessful IVF women between T1 and T2. Interestingly, negative emotions tend to increase in the successful group, but decrease in the unsuccessful group. We found a tendentious difference in negative affectivity between the successful and unsuccessful groups at the time of embryo transfer $(F[1,77]=3.65, p=0.06)$. Furthermore, there is a tendentious increase in positive emotions of the successful group between T2 and T3, compared to an inconsiderable change in the unsuccessful group. In addition, the negative emotions remarkably decrease in the successful group, while increase in the unsuccessful group.

With respect to men's comparison ( $\triangleright$ Fig. 2 ), we found an increase in positive emotions and hopefulness in both groups at $\mathrm{T} 2$, which is just in contrast to the trend described in women. In the successful group, the opposite trend can also be seen in terms of negative emotions, since the negative emotions of men decrease, which is inconsiderable in case of the unsuccessful group. Between $\mathrm{T} 2$ and $\mathrm{T} 3$, the positive feelings of men do not change, but decrease in the unsuccessful group. We found a significant difference in positive affectivity between the successful and un- 


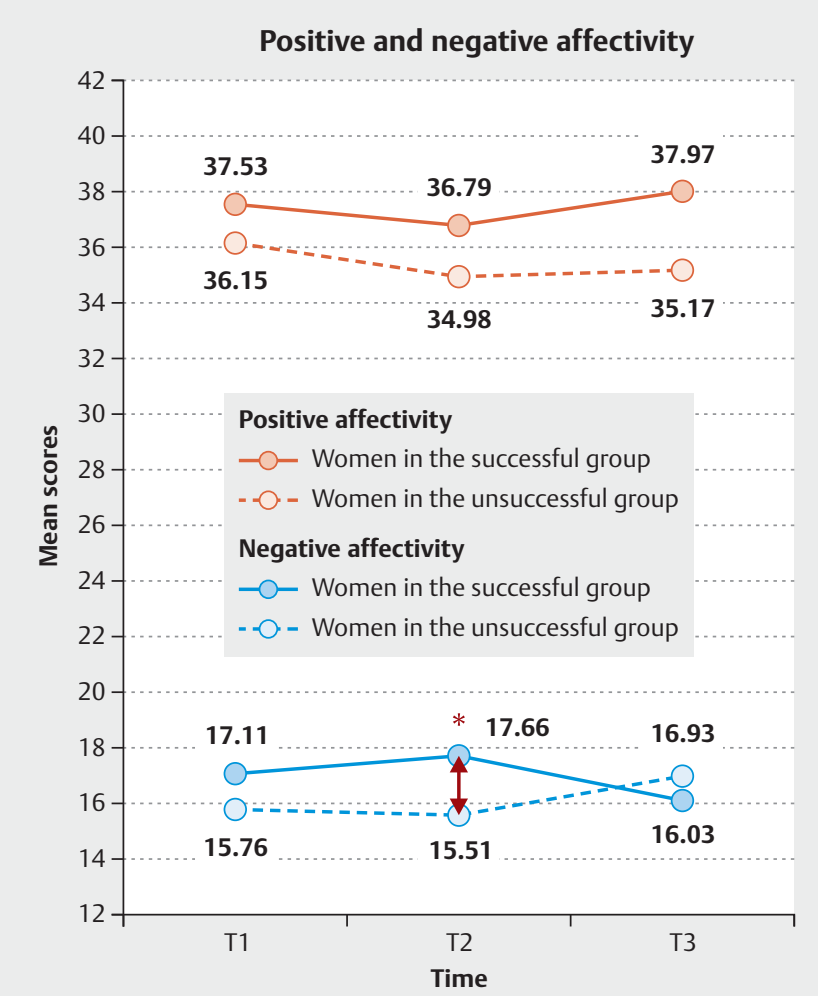

- Fig. 1 Changes of positive and negative affectivity on the Positive and Negative Affect Schedule in women undergoing successful $(n=38)$ and unsuccessful $(n=41)$ IVF treatment $\left({ }^{*} p=0.06\right)$

( $\mathrm{T} 1$ : at the beginning of the treatment; $\mathrm{T} 2$ : before embryo transfer; T3: before pregnancy test).

successful groups at T3 $(F[1,77]=4.94, p<0.05)$. By the time of pregnancy test, the negative emotions of men in the successful group do not change in contrast to men in the unsuccessful group, where the negative emotions decrease.

With regard to depression, > Fig. 3 indicates that the depression level of male and female member of unsuccessful couples is higher than that of either member of successful couples. For successful couples, women's depression score is higher than that of men. At the same time, the two curves run almost completely parallel to each other and show a downward trend between T1 and T3.

For male and female members of unsuccessful couples, we found almost the same level of depression at the beginning of the treatment, which is considerably higher than that of successful couples. Moreover, for men, the difference is proved to be significant $(F[1,78]=6.65, p<0.05)$. Between $T 1$ and $T 2$, the level of depression of men in the unsuccessful group significantly decreases $(p<0.05)$, reaching depression score of women in the successful group, but remains considerably higher than that of men in the successful group. By the time of pregnancy test, depression score of the male member of unsuccessful couples continues to decrease. In contrast, depression score of the female member of unsuccessful couples significantly increases $(p<0.05)$ between $\mathrm{T} 2$ and T3 and exceeds baseline level.

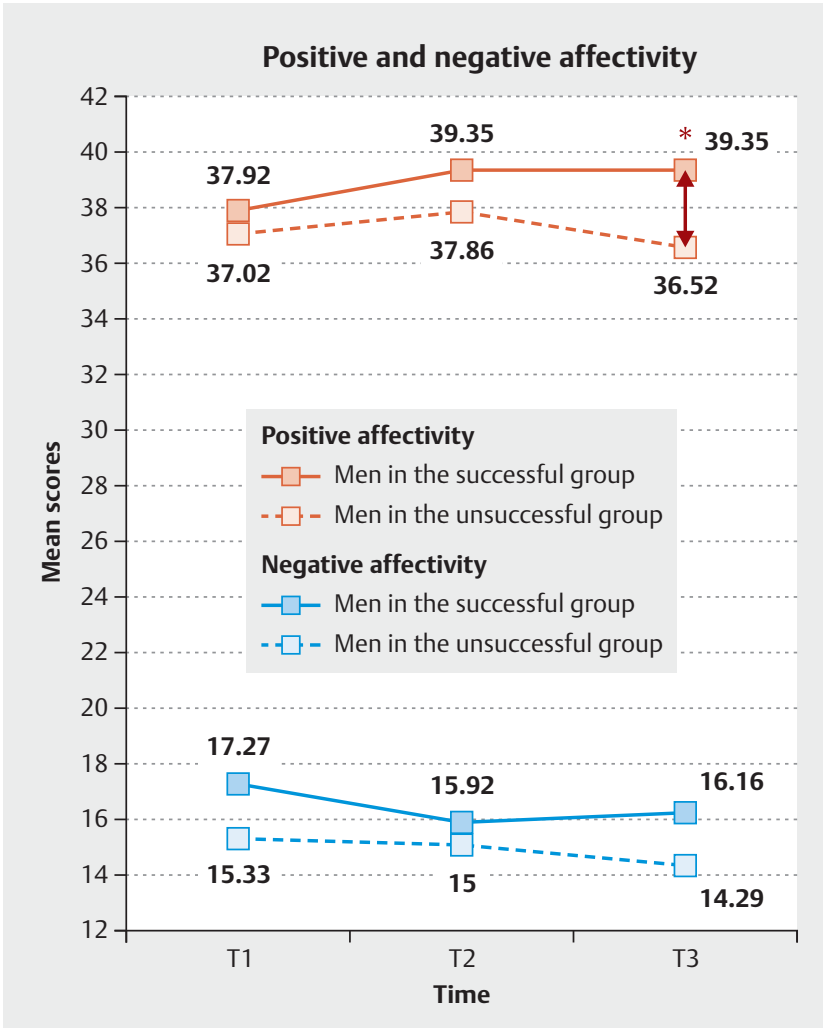

- Fig. 2 Changes of positive and negative affectivity on the Positive and Negative Affect Schedule in men undergoing successful $(n=37)$ and unsuccessful $(n=42)$ IVF treatment $\left({ }^{*} p<0.05\right)$

(T1: at the beginning of the treatment; $\mathrm{T} 2$ : before embryo transfer; T3: before pregnancy test).

\section{Discussion}

Our study was carried out in order to clarify whether the negative change in emotional state and depression is specific to IVF couples compared to the general adult and patient populations. We also wanted to explore emotional state changes in couples undergoing successful and unsuccessful IVF treatment across stages of the cycle ( $\mathrm{T} 1$ : at the beginning of the treatment, $\mathrm{T} 2$ : before embryo transfer, T3: before pregnancy test). Furthermore, we wanted to explore if there is an association between the treatment success and the emotional state of IVF couples, and the emotional relationship between men and women.

The positive and negative affectivity of infertile couples (both men and women) were found to be significantly better compared to the patient population, which suggests that no awareness of disease relates to infertility among infertile couples. It appears that the awareness of disease would reduce motive for childbearing or increase fear of risk of having a child with a birth defect. According to our research, the infertility problem does not imply disease-related conditions, in spite of the fact that infertility is a medically treated disease in a health care facility. Our study participants evaluate their status as a special situation rather than a disease. Compared to the general adult population, they show significantly lower levels of depression and trait anxiety. The more fa- 


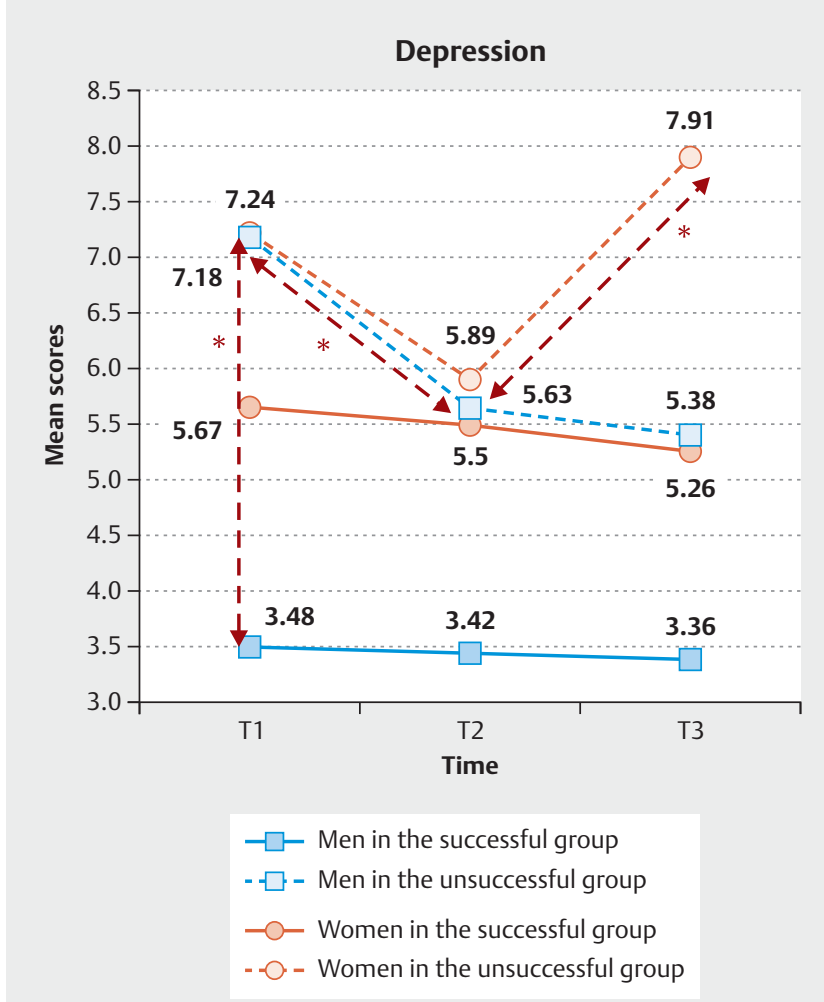

- Fig. 3 Changes of depression on the short form of Beck Depression Inventory in men and women undergoing successful and unsuccessful IVF treatment $\left({ }^{*} \mathrm{p}<0.05\right)(\mathrm{T} 1$ : at the beginning of the treatment; T2: before embryo transfer; T3: before pregnancy test).

vorable results of infertile couples compared to the average population suggest that indicators of their emotional status are within the normal range. Similar findings were reported by Beaurepaire et al. [12], who found significantly lower depression scores among female and male inductees and repeat cycle men than the community norms. On the other hand, they showed that infertile couples undergoing IVF experience higher level of state anxiety irrespectively of the stage of treatment than the same-sexed community controls [12]. Our results contradict results of a German study, in which women were found to be more depressed than their female controls from the general population. However, men only showed marginally elevated depression scores compared to their age-matched controls [13]. Similar results were found in the study of Galhardo et al. [14], in which couples with an infertility diagnosis pursuing medical treatment scored higher than normal control couples in depression. Interestingly, a crosssectional Hungarian study [15] found that infertile women were more depressed than the normative adult population, while infertile men did not differ significantly from their male controls regarding depression. No significant difference was observed in men and women in terms of anxiety.

Our results are in accordance with some previous results in which most infertile couples show resilience throughout fertility treatment [31]. IVF patients presumably have more effective coping strategies and manage to handle emotional strain during the treatment in comparison to those who do not even undertake the treatment. Our results indicate that the desire to have a child and all the commitments and life goals related to it may mobilize positive energies and favorable coping mechanisms among these people, which may preclude the appearance of anxious and depressive feelings. This is in line with findings by Volmer et al. [32], which show that active-avoidance coping might increase the risk of developing depression or anxiety, while meaning-based coping might have a protective effect on infertile couples. It may be that anxiety and depression occur in couples who experience resignation. At the same time, the history of infertility treatment may also have an effect on psychological well-being of couples. Our study participants were undergoing their first or second IVF treatment. Resilience of couples with longer history of infertility treatment and recurrent IVF failures may decrease [33], while their levels of psychological distress may increase.

With regard to comparison of successful and unsuccessful IVF groups, it appears that the predominance of the positive emotions and keeping distance from the negative emotions in both successful and unsuccessful IVF groups during the whole IVF cycle reflect a healthy attitude, since it may only enable couples to even undertake burdens of the treatment. However, idiopathic infertility was observed in the unsuccessful IVF group to a greater extent, which suggests that the unexplained infertility diagnosis may be associated with greater uncertainty leading to higher stress level in the relationship of couples. The unrecognized cause of infertility and individual responsibility may not mobilize sufficient coping resources in the unsuccessful group.

The decrease in positive emotions in both successful and unsuccessful IVF women between $\mathrm{T} 1$ and $\mathrm{T} 2$ suggests that women have to experience an unpleasant procedure at $\mathrm{T} 2$, when the embryo transfer takes place. In addition, our results are aligned with studies that found a significant decrease in positive affect after hormone use compared to before hormone use [16]. Interestingly, negative emotions increased in the successful group but decreased in the unsuccessful group, which may indicate an increased concern for success in the subsequently pregnant group. A slight change in negative emotions can mobilize limited coping resources in the unsuccessful group. We found a tendentious difference in negative affectivity between the successful and unsuccessful IVF women at the time of embryo transfer, thus women in the successful group presumably face and cope with the unpleasant experience of the expected procedure, which may be the "price of success". The higher level of negative affectivity may lead women in the successful group to pay more attention to developing their lifestyle, complying with medical instructions, proposing that it becomes a protective factor. The awareness of negative emotions seems to mobilize their coping potential. This is in line with findings by Moreno-Rosset et al. [34], which show that a non-clinical level of state-anxiety may be beneficial for achieving pregnancy. In contrast, some studies do not confirm the positive association between negative emotions, anxiety and IVF pregnancy, although they included different measurement occasions. Turner et al. [22] observed in a sample of women undergoing IVF that there is no association between state anxiety level prior to ovarian stimulation and pregnancy rate, but a lower level of state anxiety one day prior to oocyte retrieval is associated with higher 
pregnancy rate. According to the study of Lintsen et al. [23], the anxiety gain score from pretreatment to oocyte retrieval does not affect the pregnancy rate after IVF.

Our interpretation is also confirmed by the fact that there was a tendentious increase in positive emotions of the successful group between $\mathrm{T} 2$ and $\mathrm{T} 3$, compared to an inconsiderable change in the unsuccessful group. Additionally, the negative emotions remarkably decreased in the successful group, while increased in the unsuccessful group. For women in the successful group, anxiety may not disorganize behavior, but may facilitate it and become the basis of the positive emotions towards success. In contrast, women in the unsuccessful group may be debilitated by their anxiety; therefore, they may be unable to work for success, their emotions change in a negative direction.

Thus, the decisive role of emotions is reflected by the tendentious difference in negative affectivity between the two groups at the time of embryo transfer and the increase of positive emotions in the successful group contrary to the unsuccessful group before the pregnancy test, when couples are not aware of the successful or unsuccessful outcome of the treatment yet, indicating that the subsequently pregnant women trust in success. At the same time, the negative emotions decrease considerably in the successful group and increase in the unsuccessful group. Overall, emotional attitudes towards childbearing change in a positive direction among women in the successful group, in contrast to a negative direction among women in the unsuccessful group, which can lead to depression. These findings add to the existing literature by suggesting that it is the emotional attitude that psychologically differentiates between the successful and unsuccessful IVF women. The successful group seems to reflect emotional dynamics being consistent with the situation, while women in the unsuccessful group tend to show indifference, accordingly they may be less emotionally involved in the situation. It may be the result of emotional exhaustion due to infertility treatment, which presumably affects childbearing motives and the success of treatment. Consequently, it appears that emotional attitudes of couples towards childbearing need to be more consciously shaped, since they can be associated with the treatment outcome.

With regard to men's comparison, we found an increase in positive emotions and hopefulness in both groups at $\mathrm{T} 2$, which is just in contrast to the trend described in women, where the physical discomfort and risk of the treatment were accompanied by a decrease of the positive emotions. In the successful group, the opposite trend was also seen in terms of negative emotions, since the negative emotions of men decreased. In the relationship of couples, it suggests that the female partner of successful couples experiencing the unpleasant treatment expects and emerges more emotional support from the male partner. The decrease in men's negative affectivity may convey encouragement, but in the case of unsuccessful couples, it is inconsiderable. Between T2 and T3, the positive feelings of men did not change but definitely decreased in unsuccessful couples. We hypothesize that this result implies that, in case of successful couples, men may provide emotional support to their partner steadily until the end of treatment, while it remarkably decreases in the unsuccessful group by the time of pregnancy test; accordingly the female partner of couples may be left alone. Between T2 and T3, the negative emotions of men in the successful group did not change, thus besides emotional support they may express their concerns, in contrast to men in the unsuccessful group, where the negative emotions decreased, which also suggests a reduction in concern, as the burden of childbearing may cease due to assuming unsuccessful outcome of treatment. Consequently, the combination of these results suggests a change toward a more indifferent emotional attitude in the unsuccessful group.

Comparison of emotional state changes of women and men in connection with successful and unsuccessful IVF treatment shows that the emotional attitude of the male partner of the couple is crucial. In successful IVF couples, decrease in positive affectivity and increase in negative affectivity for women by the time of embryo transfer is accompanied by an increase in positive affectivity for men, which remains until the time of pregnancy test, thereby presumably providing emotional support to their partner for the purpose of having a child. For unsuccessful couples, this is contrary to the pattern described in the successful group. The negative feelings of women in the unsuccessful group are remarkably less intense, which can imply a lower degree of emotional involvement. Women in the successful and unsuccessful group almost significantly differ from each other in negative affectivity at the time of embryo transfer; accordingly, subsequently pregnant women may experience the physical discomfort and risk of the treatment to a greater extent, which presumably mobilizes coping potential. Men in the successful and unsuccessful group do significantly differ from each other in positive affectivity at the time of pregnancy test, which reflects higher emotional support among men in the successful group. In the unsuccessful group, men's negative emotions are less intense, suggesting a lower degree of emotional involvement. They may lose hope and faith and experience inability, thereby weakening their emotional support provided to their partner. The study of Chen et al. [35] supports the relationship between marital satisfaction and the success of treatment.

The direction of change in positive and negative emotions is confirmed by direction of change in depression. Compared to successful couples, the higher level of depression may not enable unsuccessful couples to experience the positive feeling of having a child; it can reduce the strength of childbearing motives and the coping potential related to it. The higher level of depression among women compared to men can be derived from the greater physical burden of the treatment imposed on women. The significant decrease in depression of men in the unsuccessful group between T1 and T3 may indicate relief as anticipating the final outcome, since they may not experience failure as women in the unsuccessful group whose depression scores significantly increase. The anticipation of failure may lead to an increase in depression for women, while a decrease for men. Our results raise further research questions about childbearing and other motivations of the male partner of unsuccessful couples. Perhaps, they might not be motivated enough in having children or they might have conflicting motives that need to be further investigated. There may be an inadequate emotional synchrony in unsuccessful couples in terms of decision to have a child, the lack of emotional rapport and the emotional distance between the partners may hinder the purpose of conception. Not only conscious, but unconscious fears or rejec- 
tion can affect changes in emotional state. Our results are in line with the results of previous studies that showed that a higher level of depression is associated with lower pregnancy rates in women [18]. In addition, Slade et al. [36] observed an increase within the IVF cycle in the degree of depressive symptoms of women 46 weeks after embryo replacement, compared to the beginning of the treatment. According to the study of Yong et al. [21], women undergoing IVF treatment are most vulnerable to psychological distress at the stage of pregnancy test. In contrast, some studies found no statistically significant differences between women undergoing a successful and unsuccessful cycle of assisted reproductive technology in pretreatment emotional distress (e.g. anxiety, depression) [19]. Similar findings were reported by Matthiesen et al. [20], who found no significant association between depression and clinical pregnancy. Moreover, there is no data concerning the association between depression in men and the treatment outcome.

The novelty of our study is that we examine infertility not only along with the biological process of IVF treatment, but also changes in the emotional state of both partners at the same stages of the treatment, from which we can conclude emotional relationship of infertile couples determining intentions towards having a child.

One limitation of our study might be that we have not followed the couples after the pregnancy test; therefore, data are not available concerning further development of the pregnancy and live birth. Although our study does not control for all possible negative prognostic factors, every couple who participated in our research and decided to undergo the treatment was assessed for age, AMH (Anti-Mullerian Hormone), AFC (Antral Follicle Count), and BMI (Body Mass Index) and made their informed decision being aware of these prognostic factors. In spite of the fact that both partners were emphatically asked to answer the questionnaires separately without communicating with his or her partner, and most participants reported at the next visit that they followed our instructions, they were allowed to complete the questionnaires at home, which is a potential confounder. Another limitation might be that we have no information if couples took a pregnancy test at home between the time of the embryo transfer and the pregnancy blood test, which could influence their emotional state and act as a confounding factor. Furthermore, pregnancy is accompanied by multiple hormonal changes [37], possibly influencing emotional state in successful IVF women before the pregnancy test, and acting as a confounding factor as well. Nevertheless, according to a systematic review, the occurrence of depressive symptoms during the first trimester of pregnancy is comparable to that of the general female population [38].

Our results suggest the importance of couples' emotional dynamics in childbearing. The lack of emotional synchrony between partners is a possible explanation for an unsuccessful IVF attempt. Participation of men in the IVF treatment is at least as determinant psychologically as the role of women in undergoing the biological process of the treatment. The emotional attitude and support of men become a determining factor in the biological success of women. Our findings suggest that it is worth exploring feelings and aspirations of couples related to childbearing and parenthood, as this may increase the efficiency of assisted reproduc- tion. Moreover, adaptive coping with infertility and stressful, overwhelming fertility procedures may offer an opportunity for posttraumatic growth [39].

\section{Conclusions}

Our study suggests the importance of couples' emotional dynamics in having a child and an association between couples' emotional reactions during the IVF cycle and the treatment success, which is also confirmed by the higher proportion of couples with unexplained infertility in the unsuccessful group. Therapeutic counseling including couple therapy should aim to reduce the sense of helplessness of men so that they can get emotionally involved to a greater extent and provide emotional support to their partner. Moreover, treatment of depression from the onset of the treatment and giving hope to couples in the most crucial period between the time of embryo transfer and pregnancy test could further increase the success of treatment.

\section{Acknowledgements}

We want to express our appreciation to all the couples who participated in our research. We are also grateful to the staff of the Assisted Reproductive Centre who helped us recruit them.

\section{Conflict of Interest}

The authors declare that they have no conflict of interest.

\section{References}

[1] Zegers-Hochschild F, Adamson GD, de Mouzon J et al. International Committee for Monitoring Assisted Reproductive Technology (ICMART) and the World Health Organization (WHO) revised glossary of ART terminology, 2009. Fertil Steril 2009; 92: 2683-2687

[2] Cui W. Mother or nothing: the agony of infertility. B World Health Organ 2010; 88: 881-882

[3] Kovács P. Meddőség kezelése centrális hypogonadizmus kapcsán [Treatment of infertility in central hypogonadism]. Magyar Nőorvosok Lapja 2006; 69: 447-452

[4] Davajan V, Israel R. Diagnosis and medical Treatment of Infertility. In Stanton AL, Dunkel-Schetter C, eds. Infertility. The Springer Series on Stress and Coping. Boston: Springer; 1991: 17-28

[5] Brugo-Olmedo S, Chillik C, Kopelman S. Definition and causes of infertility. Reprod Biomed Online 2001; 2: 173-185

[6] Kupka MS, Ferraretti AP, de Mouzon J et al. Assisted reproductive technology in Europe, 2010: results generated from European registers by ESHRE. Hum Reprod 2014; 29: 2099-2113

[7] Hammond CB, Stillman RJ. Infertility and assisted Reproduction. In: Scott JR, Di Saia PJ, Hammond CB, Spellacy WN, eds. Danforth's Obstetrics and Gynecology. 8th ed. Philadelphia: Lippincott Williams and Wilkins; 1999: 649-667

[8] Bernard A, Krizsa F. A meddőségről általában [Infertility in general]. In: Kaáli SG, Bernárd A, Kovács P, eds. A meddőség korszerű diagnosztikája és kezelése [Advanced diagnostics and treatment of infertility]. Budapest: Medicina; 2006: 13-23

[9] Patel A, Sharma PSVN, Narayan P et al. Prevalence and predictors of infertility-specific stress in women diagnosed with primary infertility: A clinic-based study. J Hum Reprod Sci 2016; 9: 28 
[10] Lin YH, Chueh KH, Lin JL. Somatic symptoms, sleep disturbance and psychological distress among women undergoing oocyte pick-up and in vitro fertilisation-embryo transfer. J Clin Nurs 2016; 25: 1748-1756

[11] Hajela S, Prasad S, Kumaran A et al. Stress and infertility: a review. Int J Reprod Contracept Obstet Gynecol 2016; 5: 940-943

[12] Beaurepaire J, Jones $M$, Thiering $P$ et al. Psychosocial adjustment to infertility and its treatment: male and female responses at different stages of IVF/ET treatment. J Psychosom Res 1994; 38: 229-240

[13] Beutel M, Kupfer J, Kirchmeyer P et al. Treatment-related stresses and depression in couples undergoing assisted reproductive treatment by IVF or ICSI. Andrologia 1999; 31: 27-35

[14] Galhardo A, Cunha M, Pinto-Gouveia J. Psychological aspects in couples with infertility. Sexologies 2011; 20: 224-228

[15] Szigeti J, Konkolÿ TB. A meddőség pszichés velejárói egy hazai pilotvizsgálat tükrében [Psychological aspects of infertility: results of a Hungarian pilot study]. Magyar Pszichológiai Szemle 2012; 67: 713-731

[16] Klonoff-Cohen $\mathrm{H}$, Chu E, Natarjan L et al. A prospective study of stress among women undergoing in vitro fertilization and gamete intrafollopian transfer. Fertil Steril 2001; 76: 675-687

[17] Csemiczky Gy, Landgren BM, Collins A. The influence of stress and state anxiety on the outcome of IVF-treatment: psychological and endocrinological assessment of Swedish women entering IVF-treatment. Acta Obstet Gyn Scan 2000; 79: 113-118

[18] Smeenk JM], Verhaak CM, Eugster A et al. The effect of anxiety and depression on the outcome of in-vitro fertilization. Hum Reprod 2001; 16 : 1420-1423

[19] Boivin J, Griffiths E, Venetis CA. Emotional distress in infertile women and failure of assisted reproductive technologies: meta-analysis of prospective psychosocial studies. BMJ 2011; 342: d223

[20] Matthiesen SMS, Frederiksen Y, Ingerslev H] et al. Stress, distress and outcome of assisted reproductive technology (ART): a meta-analysis. Hum Reprod 2011; 26: 2763-2776

[21] Yong P, Martin C, Thong J. A comparison of psychological functioning in women at different stages on in vitro fertilization treatment using the Mean Affect Adjective Check List. J Assist Reprod Gen 2000; 17: 553556

[22] Turner K, Reynolds-May MF, Zitek EM et al. Stress and anxiety scores in first and repeat IVF cycles: a pilot study. PLoS One 2013; 8: e63743

[23] Lintsen AM, Verhaak CM, Eijkemans M] et al. Anxiety and depression have no influence on the cancellation and pregnancy rates of a first IVF or ICSI treatment. Hum Reprod 2009; 24: 1092-1098

[24] Watson D, Clark LA, Tellegen A. Development and validation of brief measures of positive and negative affect: The PANAS scales. J Pers Soc Psychol 1988; 54: 1063-1070

[25] Gyollai Á, Simor P, Köteles F et al. A Pozitív és Negatív Affektivitás Skála (PANAS) eredeti és rövidített változatának pszichometriai jellemzői [Psy- chometric properties of the Hungarian version of the original and the short form of the Positive and Negative Affect Schedule (PANAS)]. Neuropsychopharmacol Hung 2011; 13: 73-79

[26] Ágoston G, Szili I. Diagnosztikus kérdőívek és tünetbecslő skálák [Diagnostic Questionnaires and Symptom Assessment Scales]. In: Füredi J, Németh A, Tariska P, eds. A pszichiátria magyar kézikönyve [The Hungarian Handbook of Psychiatry]. Budapest: Medicina; 2001: 176-183

[27] Kopp M, Fóris N. A szorongás kognitív viselkedésterápiája [Cognitive-behavioural Therapy of Anxiety]. Budapest: Végeken; 1993

[28] Rózsa S, Szádóczky E, Füredi ]. A Beck Depresszió Kérdőív rövidített változatának jellemzői hazai mintán [Features of the shortened form of Beck Depression Inventory in a Hungarian sample]. Psychiat Hung 2001; 16: 379-397

[29] Sipos K, Sipos M. Állapot-Vonás Szorongás Kérdőív [State-Trait Anxiety Inventory]. In: Perczel-Forintos D, Kiss Zs, Ajtay Gy, eds. Kérdőívek, becslőskálák a klinikai pszichológiában [Questionnaires and Scales in clinical Psychology]. Budapest: Országos Pszichiátriai és Neurológiai Intézet; 1978: 50-52

[30] Susánszky É, Székely A. A Hungarostudy 2013 felmérés módszertana [The methodology of Hungarostudy 2013 Survey]. In: Susánszky É, Szántó Zs, eds. Magyar lelkiállapot [The Hungarian mental state]. Budapest: Semmelweis; 2013: 13-21

[31] Gameiro S. Infertility. In: Friedman HS, eds. Encyclopedia of mental Health (Second Edition). Waltham: Academic Press; 2016: 375-383

[32] Volmer L, Rösner S, Toth B et al. Infertile Partners' Coping Strategies Are Interrelated-Implications for Targeted Psychological Counseling. Geburtsh Frauenheilk 2017; 77: 52-58

[33] Kreuzer VK, Kimmel M, Schiffner ] et al. Possible Reasons for Discontinuation of Therapy: an Analysis of 571071 Treatment Cycles From the German IVF Registry. Geburtsh Frauenheilk 2018; 78: 984-990

[34] Moreno-Rosset C, Arnal-Remón B, Antequera-jurado R et al. Anxiety and psychological wellbeing in couples in transition to parenthood. Clínica y Salud 2016; 27: 29-35

[35] Chen D, Zhang JP, jiang $L$ et al. Factors that influence in vitro fertilization treatment outcomes of Chinese men: A cross-sectional study. Appl Nurs Res 2016; 32: 222-226

[36] Slade P, Emery J, Lieberman BA. A prospective, longitudinal study of emotions and relationships in in-vitro fertilization treatment. Hum Reprod 1997; 12: 183-190

[37] Steiner M, Dunn E, Born L. Hormones and mood: from menarche to menopause and beyond. J Affect Disord 2003; 74: 67-83

[38] Bennett HA, Einarson A, Taddio A et al. Prevalence of depression during pregnancy: systematic review. Obstet Gynecol 2004; 103: 698-709

[39] Nagy E, Nagy BE. Coping with infertility: Comparison of coping mechanisms and psychological immune competence in fertile and infertile couples. J Health Psych 2016; 21: 1799-1808 